\title{
Protective effect of crocetin from Crocus sativus L. on myocardial ischemia-reperfusion injury in rats
}

\author{
Chengxiao LIU ${ }^{1 *, * *}\left(\mathbb{D}\right.$, Erlian SUN ${ }^{2 * *}$, Wenjun MENG ${ }^{1}$, Guoqing SUN ${ }^{1}$
}

\begin{abstract}
This study investigated the protective effect of crocetin from Crocus sativus L. on myocardial ischemia-reperfusion injury (MIRI) in rats. Sixty SD rats were randomly divided into sham-operated, model, and low-, medium- and high-dose crocetin groups. Later 3 groups were intragastrically administrated with 10,20 and $40 \mathrm{mg} / \mathrm{kg}$ crocetin from Crocus sativus L., respectively, for 1 week. On the 8th day, the MIRI model was established in the later 4 groups. The blood biochemical indexes, hemodynamic indexes, myocardial infarct size, myocardial antioxidant indexes and myocardial expressions of B-cell lymphoma-2 (Bcl-2), Bcl-2 associated X protein (Bax), serine/threonine kinase (Akt) and phosphorylated Akt (p-Akt) protein were determined. Results showed that, compared with model group, in high-dose crocetin group the left ventricular systolic pressure, $+\mathrm{d} p / \mathrm{d} t_{\max }$ and $-\mathrm{d} p / \mathrm{d} t_{\max }$, myocardial superoxide dismutase and glutathione peroxidase levels, and myocardial Bcl-2/Bax ratio and p-Akt/Akt ratio were significantly increased, and the left ventricular end diastolic pressure, myocardial infarct size, serum lactate dehydrogenase, creatine kinase-MB, cardiac troponin I, tumor necrosis factor- $\alpha$, interleukin- $1 \beta$, interleukin- 6 and malondialdehyde levels were significantly decreased (all $\mathrm{P}<0.05$ ). In conclusion, crocetin from Crocus sativus $L$. has protective effects on MIRI in rats.
\end{abstract}

Keywords: crocetin; ischemia-reperfusion injury; Bcl-2; Bax; Akt.

Practical Application: Crocetin from Crocus sativus L. has potential for clinical prevention of myocardial ischemia-reperfusion injury.

\section{Introduction}

With the increase of elderly population proportion and the improvement of people's living standard, the incidence of ischemic heart disease is increasing year by year. In recent years, although the vascular recanalization and reconstruction techniques such as thrombolysis, interventional therapy and coronary artery bypass grafting can quickly restore the coronary perfusion, the incidence of myocardial ischemia-reperfusion injury (MIRI) is still high, and it has become an important cause of death in ischemic heart disease (Venardos et al., 2007). MIRI can lead to the myocardial irreversible damage, and cause the myocardial morphological changes. It is characterized by myocardial fiber rupture, arrangement disorder, interstitial edema and inflammatory cell infiltration (Zhai et al., 2000; Wang et al., 2018). The mechanism of MIRI may involve oxidative stress and inflammatory reaction (Cheng et al., 2015; Hu et al., 2015). How to effectively delay and control the occurrence and development of MIRI is an urgent problem in the prevention and treatment of ischemic heart disease. Crocetin is the active substance extracted from the stigma of Crocus sativus $L$., a popular traditional Chinese medicine. Previous study has proved that, crocin has obvious antiatherogenic and anti-hypertension effect (Rameshrad et al., 2018). In addition, crocetin has protective effects on myocardium, and its mechanism may be related to its anti-lipid peroxidation, inhibition of free radical production and calcium overload, and inhibition of cardiomyocyte apoptosis (Shen et al., 2006; Zhang et al., 2009). However, the action mechanism of crocetin on myocardial ischemia is not very clear. It is reported that, the inflammatory response and oxidative stress are involved in the occurrence and development of MIRI (Vinten-Johansen et al., 2007; Yu et al., 2016). This study investigated the protective effect of crocetin on MIRI in rats and the related mechanisms. The objective was to provide a experimental basis for the development of crocetin related medicines and the clinical prevention and treatment of MIRI.

\section{Materials and methods}

\subsection{Animal grouping and treatment}

Sixty Sprague-Dawley rats $(250 \pm 20 \mathrm{~g})$ were randomly divided into 5 groups: sham-operated group, model group, and low-, middle- and high-dose crocetin groups, 12 rats in each group. The rats in low-, middle- and high-dose baicalin group were intragastrically administrated with crocetin (extracted from the stigma of Crocus sativus L.; HPLC purity $\geq 98 \%$ ), with dose of 10,25 and $40 \mathrm{mg} / \mathrm{kg}$, respectively (according to the results of pre-experiments). The rats in sham-operated and model groups were intragastrically administrated with normal saline. The intraperitoneal injection was performed once per day, and was continued for 1 week before MIRI modeling. 


\subsection{Establishment of MIRI model}

According to the reported method (Liang et al., 2010), rats were anaesthetized by intraperitoneal injection of $10 \%$ chloral hydrate $(300 \mathrm{mg} / \mathrm{kg})$ and were fixed in supine position. After shearing, the neck was incised and the right carotid artery was isolated. The trachea was exposed and incised, and the mechanical ventilation was performed using small-animal ventilator. The breathing frequency was controlled at about $70 \mathrm{time} / \mathrm{min}$. The electrodes were subcutaneously inserted in the extremities, and were connected with the biological function experiment system. The skin on the left margin of sternum was longitudinally incised. The chest between the fourth and fifth ribs was opened. The pericardium was cut, and the heart was fully exposed. A 5-0 silk was used to cross the surface layer of heart (depth of about $1.5 \mathrm{~mm}$ ) at the position $2 \mathrm{~mm}$ under left atrium. The anterior descending branch of left coronary artery was ligated for inducing myocardial ischemia for $30 \mathrm{~min}$. Then, the ligation was released for reperfusion for $2 \mathrm{~h}$. The signs of successful MIRI establishment were as follows: in ischemia, the local myocardium was pale or purple, and in electrocardiogram the ST-segment was obviously elevated or T wave was elevated; in reperfusion, the ischemic myocardium turned red, and elevated ST segment decreased by more than $50 \%$. In sham-operated group, the silk crossed the surface layer of heart, but the anterior descending branch of left coronary artery was not ligated, which lasted for $2 \mathrm{~h}$.

\subsection{Detection of hemodynamic indexes}

After establishment of MIRI model, the cervical lymph nodes of rats were removed, and the right carotid artery was isolated. PE50 artery catheter was inserted into the left ventricle via right carotid artery. The left ventricular systolic pressure (LVSP), left ventricular end diastolic pressure (LVEDP), maximum rate of left ventricular pressure rise $\left(+\mathrm{d} p / \mathrm{d} t_{\text {max }}\right)$ and maximum the rate of decline $\left(-\mathrm{d} p / \mathrm{d} t_{\max }\right)$ were recorded detected by MD3000 biological function experiment system (Anhui Zhenghua Biological Instrument Equipment Co., Ltd., Huaibei, China).

\subsection{Determination of serum biochemical indexes}

Rats were anesthetized using $2 \%$ sodium pentobarbital (Sigma-Aldrich Corp., MO, USA) by intraperitoneal injection $(20 \mathrm{mg} / \mathrm{kg})$. The abdominal cavity was opened. The blood of the abdominal aorta was taken, followed by centrifugation at $2000 \mathrm{rpm}$ for $10 \mathrm{~min}$. The serum lactate dehydrogenase (LDH), creatine kinase-MB (CK-MB) and cardiac troponin I (cTnI) were detected using the spectrophotometry. The serum tumor necrosis factor- $\alpha$ (TNF- $\alpha$ ), interleukin (IL)- $1 \beta$ and IL-6 levels were determined using enzyme linked immunosorbent assay. The procedures were in accordance to the instructions of kits (Shanghai Sangon Biological Engineering Technology And Service Co., Ltd., Shanghai, China).

\subsection{Determination of myocardial infarction size}

According to the reported method (Haugan et al., 2006), the heart was cut from the tip to the base, with the direction parallel to atrioventricular sulcus. The left ventricle was chopped, and was incubated in 1\% 2,3,5-chloride three phenyl tetrazole solution for $15 \mathrm{~min}$. After staining, the infarcted myocardium presented pale, and the active myocardium presented red. The unstained non-ischemic area was separated from the red-stained ischemic area with an operating blade. The infarct volume of the red-stained myocardium was measured in a vessel with buffered liquid. The myocardial infarction size was presented by the ratio of infarcted area volume to total left ventricular volume.

\subsection{Determination of myocardial superoxide dismutase, glutathione peroxidase and malondialdehyde levels}

The heart of rats was taken, followed by rinsing with saline. The $10 \%$ myocardial homogenate was prepared. After centrifugation at $2000 \mathrm{rpm}$ for $10 \mathrm{~min}$, the supernatant was obtained. The superoxide dismutase (SOD) level was detected by xanthine oxidase method (Chen et al., 2016). The glutathione peroxidase (GSH-Px) level was measured by reduced glutathione depletion method (Fläring et al., 2003). The content of malondialdehyde (MDA) was analyzed by thiobarbituric acid colorimetric assay (Chen et al., 2016).

\subsection{Determination of myocardial Bcl-2, Bax, Akt and p-Akt protein expressions}

The myocardial tissue was homogenized, and the protein was extracted using RIPA lysis buffer (Sigma-Aldrich Corp., MO, USA). The protein concentration was determined by Coomassie brilliant blue method. The 10\% SDS-PAGE (Sigma-Aldrich Corp., MO, USA) was performed for $3 \mathrm{~h}$, then the separated protein was transferred to the PVDF membrane (Sigma-Aldrich Corp., MO, USA). After washing the membrane with PBS (Fuzhou Maixin Biotechnology Development Co., Ltd., Fuzhou, China) for 3 times, 5\% evaporated milk (Fuzhou Maixin Biotechnology Development Co., Ltd., Fuzhou, China) was used to block the non-specific antigen for $2 \mathrm{~h}$. After blocking, the membranes were incubated with primary antibody overnight at $4{ }^{\circ} \mathrm{C}$, followed by washing with PBS. The horseradish peroxidase-labeled second antibody was added, followed by incubation at room temperature for $2 \mathrm{~h}$. Visualization was accomplished by the enhanced chemiluminescence (ECL plus Western-blotting detection system, GE Healthcare Life Sciences, MA, USA). The intensity of bands was calculated with Image J 1.46 analysis software (European Molecular Biology Laboratory Inc., Oxford, UK). $\beta$-actin was used as the internal reference. The B-cell lymphoma-2 (Bcl-2), Bcl-2 associated $\mathrm{X}$ protein (Bax), serine/threonine kinase (Akt) and phosphorylated serine/threonine kinase (p-Akt) primary antibodies and secondary antibodies were provided by Fuzhou Maixin Biotechnology Development Co., Ltd. (Fuzhou, China).

\subsection{Statistical analysis}

Data were presented as mean \pm SD, and analyzed using SPSS 22.0 software (SPSS Inc., Chicago, IL, USA). The comparisons among different groups were performed using single-factor analysis of variance test with SNK-q test. $\mathrm{P}<0.05$ was considered as statistically significant. 


\section{Results}

\subsection{Effects of crocetin on hemodynamics of MIRI rats}

As shown in Table 1, the LVEDP in model group was significantly higher than sham-operated group $(\mathrm{P}<0.05)$, and the LVSP, $+\mathrm{d} p / \mathrm{d} t_{\text {max }}$ and $-\mathrm{d} p / \mathrm{d} t_{\text {max }}$ in model group were significantly lower than sham-operated group, respectively $(\mathrm{P}<0.05)$. Compared with model group, the LVEDP in 3 crocetin groups was significantly decreased, respectively $(\mathrm{P}<0.05)$, the LVSP and $+\mathrm{d} p / \mathrm{d} t_{\max }$ in high-dose crocetin group, and the $-\mathrm{d} p / \mathrm{d} t_{\max }$ in middle- and high-dose crocetin groups were significantly increased, respectively $(\mathrm{P}<0.05)$.

\subsection{Effects of crocetin on miocardial infarction size of MIRI rats}

Figure 1 showed that, there was no obvious miocardial infarction in sham-operated group. The miocardial infarction size in middle- and high-dose crocetin groups was $36.5 \pm 4.1 \%$ and $27.6 \pm 3.2 \%$, respectively, significantly lower than $46.1 \pm 5.8 \%$ in model group, respectively $(\mathrm{P}<0.05)$.

\subsection{Effects of crocetin on myocardial injury markers of MIRI rats}

Compared with sham-operated group, the serum LDH, $\mathrm{CK}-\mathrm{MB}$ and $\mathrm{cTnI}$ levels in rats in model group were significantly increased, respectively $(\mathrm{P}<0.05)$. Compared with model group, the LDH level in middle- and high-dose crocetin groups,
CK-MB level in high-dose crocetin groups, and cTnI level in 3 crocetin groups were significantly decreased, respectively $(\mathrm{P}<0.05)$ (Table 2).

\subsection{Effects of crocetin on serum TNF- $\alpha, I L-1 \beta$ and IL-6 levels in MIRI rats}

As shown in Table 3, compared with sham-operated group, the serum TNF- $\alpha$, IL- $1 \beta$ and IL- 6 levels in model group were significantly increased, respectively $(\mathrm{P}<0.05)$. Compared with

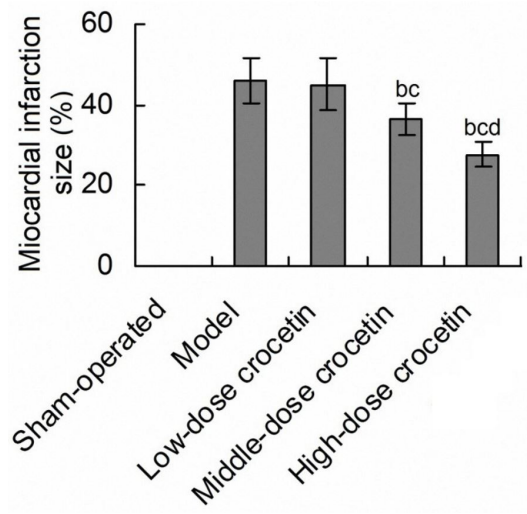

Figure 1. Miocardial infarction size in different groups. ${ }^{b} \mathrm{P}<0.05$ compared with model group; ${ }^{\mathrm{P}} \mathrm{P}<0.05$ compared with low-dose crocetin group; ${ }^{\mathrm{d}} \mathrm{P}<0.05$ compared with middle-dose crocetin group.

Table 1. Hemodynamics of rats in different groups.

\begin{tabular}{lcccc}
\hline \multicolumn{1}{c}{ Group } & LVSP $(\mathrm{mmHg})$ & LVEDP $(\mathrm{mmHg})$ & $+\mathrm{d} p / \mathrm{d} t_{\max }(\mathrm{mmHg})$ & $-\mathrm{d} p / \mathrm{d} t_{\max }(\mathrm{mmHg})$ \\
\hline Sham-operated & $139.5 \pm 27.1$ & $3.5 \pm 0.9$ & $4078.3 \pm 432.8$ & $3678.9 \pm 421.7$ \\
Model & $93.3 \pm 18.3^{\mathrm{a}}$ & $11.9 \pm 2.3^{\mathrm{a}}$ & $2633.6 \pm 367.3^{\mathrm{a}}$ & $2034.0 \pm 389.3^{\mathrm{a}}$ \\
Low-dose crocetin & $97.2 \pm 20.7^{\mathrm{a}}$ & $8.2 \pm 1.8^{\mathrm{ab}}$ & $2845.2 \pm 401.9^{\mathrm{a}}$ & $2210.2 \pm 429.0^{\mathrm{a}}$ \\
Middle-dose crocetin & $110.3 \pm 21.9^{\mathrm{a}}$ & $6.7 \pm 1.9^{\mathrm{ab}}$ & $2994.7 \pm 462.5^{\mathrm{a}}$ & $2543.4 \pm 400.2^{\mathrm{ab}}$ \\
High-dose crocetin & $122.2 \pm 26.3^{\mathrm{bc}}$ & $5.6 \pm 1.2^{\mathrm{abc}}$ & $3504.7 \pm 459.9^{\mathrm{abcd}}$ & $2782.3 \pm 378.3^{\mathrm{abc}}$ \\
\hline
\end{tabular}

${ }^{\mathrm{a}} \mathrm{P}<0.05$ compared with sham-operated group; $\mathrm{b} P<0.05$ compared with model group; ${ }^{\mathrm{c}} \mathrm{P}<0.05$ compared with low-dose crocetin group; ${ }^{\mathrm{d}} \mathrm{P}<0.05$ compared with middle-dose crocetin group. LVSP, left ventricular systolic pressure; LVEDP, left ventricular end diastolic pressure; $\mathrm{d} p / \mathrm{d} t_{\text {max }^{\prime}}$ maximum left ventricular systolic/diastolic rate.

Table 2. Levels of myocardial injury markers in different groups.

\begin{tabular}{lccc}
\hline \multicolumn{1}{c}{ Group } & $\mathrm{LDH}(\mathrm{U} / \mathrm{L})$ & $\mathrm{CK}-\mathrm{MB}(\mathrm{U} / \mathrm{ml})$ & $\mathrm{cTnI}(\mathrm{pg} / \mathrm{ml})$ \\
\hline Sham-operated & $1486.6 \pm 324.36$ & $3.6 \pm 0.5$ & $25.3 \pm 2.1$ \\
Model & $3152.8 \pm 454.3^{\mathrm{a}}$ & $5.6 \pm 1.3^{\mathrm{a}}$ & $67.8 \pm 5.4^{\mathrm{a}}$ \\
Low-dose crocetin & $2864.6 \pm 469.9^{\mathrm{a}}$ & $5.5 \pm 0.8^{\mathrm{a}}$ & $60.0 \pm 4.3^{\mathrm{ab}}$ \\
Middle-dose crocetin & $2379.3 \pm 349.9^{\mathrm{abc}}$ & $4.6 \pm 0.8^{\mathrm{ac}}$ & $50.0 \pm 6.2^{\mathrm{abc}}$ \\
High-dose crocetin & $2016.6 \pm 379.5^{\mathrm{abcd}}$ & $4.2 \pm 0.6^{\mathrm{abc}}$ & $37.5 \pm 4.2^{\mathrm{abcd}}$ \\
\hline
\end{tabular}

${ }^{\text {ap }}<0.05$ compared with sham-operated group; ${ }^{\mathrm{P}} \mathrm{P}<0.05$ compared with model group; ${ }^{\mathrm{c}} \mathrm{P}<0.05$ compared with low-dose crocetin group; ${ }^{\mathrm{d}} \mathrm{P}<0.05$ compared with middle-dose crocetin group. LDH, lactate dehydrogenase; CK-MB, creatine kinase-MB; cTnI, cardiac troponin I.

Table 3. Serum TNF- $\alpha$, IL-1 $\beta$ and IL-6 levels in different groups.

\begin{tabular}{lccc}
\hline \multicolumn{1}{c}{ Group } & TNF- $\alpha(\mathrm{pg} / \mathrm{ml})$ & $\mathrm{IL}-1 \beta(\mathrm{pg} / \mathrm{ml})$ & $\mathrm{IL}-6(\mathrm{pg} / \mathrm{ml})$ \\
\hline Sham-operated & $18.0 \pm 2.5$ & $58.4 \pm 12.1$ & $44.4 \pm 9.1$ \\
Model & $140.9 \pm 25^{\mathrm{a}}$ & $183.5 \pm 32.0^{\mathrm{a}}$ & $328.8 \pm 49.8^{\mathrm{a}}$ \\
Low-dose crocetin & $123.7 \pm 22.2^{\mathrm{a}}$ & $149.0 \pm 26.7^{\mathrm{ab}}$ & $222.5 \pm 35.1^{\mathrm{ab}}$ \\
Middle-dose crocetin & $101.9 \pm 14.9^{\mathrm{abc}}$ & $113.9 \pm 20.4^{\mathrm{abc}}$ & $215.7 \pm 32.6^{\mathrm{ab}}$ \\
High-dose crocetin & $75.8 \pm 10.1^{\mathrm{abcd}}$ & $101.6 \pm 16.8^{\mathrm{abc}}$ & $190.3 \pm 29.2^{\mathrm{abc}}$ \\
\hline
\end{tabular}

${ }^{a} \mathrm{P}<0.05$ compared with sham-operated group; ${ }^{\mathrm{b}} \mathrm{P}<0.05$ compared with model group; ${ }^{\mathrm{c}} \mathrm{P}<0.05$ compared with low-dose crocetin group; ${ }^{\mathrm{d}} \mathrm{P}<0.05$ compared with middle-dose crocetin group. TNF- $\alpha$, tumor necrosis factor- $\alpha$; IL-1 $\beta$, interleukin-1 $\beta$; IL-6, interleukin-6. 
model group, the serum TNF- $\alpha$ level in middle- and high-dose crocetin groups, and IL- $1 \beta$ and IL- 6 levels in 3 crocetin groups were significantly decreased, respectively $(\mathrm{P}<0.05)$.

\subsection{Effects of crocetin on myocardial SOD, GSH-Px and MDA levels in MIRI rats}

Table 4 showed that, compared with sham-operated group, in model group the myocardial SOD and GSH-Px levels were significantly decreased, respectively $(\mathrm{P}<0.05)$, and the myocardial MDA level was significantly increased $(\mathrm{P}<0.05)$. Compared with model group, the SOD level in middle- and high-dose crocetin groups, and GSH-Px level in 3 crocetin groups were significantly increased, respectively $(\mathrm{P}<0.05)$, and the MDA level in 3 crocetin groups was significantly decreased, respectively $(\mathrm{P}<0.05)$.

\subsection{Effects of crocetin on myocardial Bcl-2 and Bax protein expression in MIRI rats}

Figure 2 showed that, compared with sham-operated group, in model group the myocardial $\mathrm{Bcl}-2$ protein expression level was decreased, and the Bax protein expression level was increased.

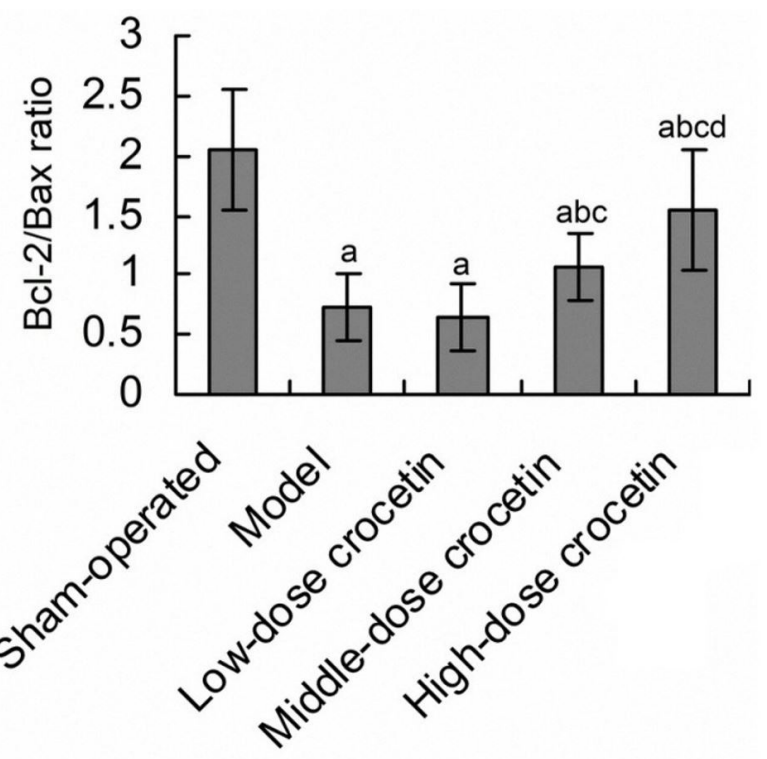

Figure 2. Myocardial Bcl-2 and Bax protein expression in different groups. ${ }^{\text {aP }}<0.05$ compared with sham-operated group; ${ }^{\text {}} \mathrm{P}<0.05$ compared with model group; ${ }^{\mathrm{P}}<0.05$ compared with low-dose crocetin group; ${ }^{\mathrm{d}} \mathrm{P}<0.05$ compared with middle-dose crocetin group. Bcl-2, B-cell lymphoma-2; Bax, Bcl-2 associated X protein.
Compared with model group, the $\mathrm{Bcl}-2$ level in treatments groups was increased, and the Bax level was decreased. The Bcl-2/Bax ratio in model group was $0.7 \pm 0.3$, significantly lower than $2.1 \pm 0.5$ in sham-operated group $(\mathrm{P}<0.05)$. The $\mathrm{Bcl}-2 / \mathrm{Bax}$ ratio in middle- and high-dose crocetin groups was $1.1 \pm 0.3$ and $1.6 \pm 0.5$, respectively, significantly higher than model group, respectively $(\mathrm{P}<0.05)$.

\subsection{Effects of crocetin on myocardial Akt and p-Akt protein expression in MIRI rats}

As shown in Figure 3, the myocardial Akt protein expression had no obvious change among different groups. Compared with sham-operated group, the myocardial p-Akt protein expression level in model group was decreased, and that in treatment groups was increased compared with model group. The p-Akt/Akt ratio in model group was $0.4 \pm 0.1$, significantly lower than $1.1 \pm 0.1$ in sham-operated group $(\mathrm{P}<0.05)$. The $\mathrm{p}-\mathrm{Akt} / \mathrm{Akt}$ ratio lowe-, middle- and high-dose crocetin groups was $0.5 \pm 0.1,0.7 \pm 0.1$ and $0.8 \pm 0.1$, respectively, significantly higher than model group, respectively $(\mathrm{P}<0.05)$.

Table 4. Myocardial SOD, GSH-Px and MDA levels in different groups.

\begin{tabular}{lccc}
\hline \multicolumn{1}{c}{ Group } & SOD (U/mgprot) & GSH-Px(U/mgprot) & MDA (mmol/mgprot) \\
\hline Sham-operated & $208.6 \pm 23.4$ & $154.0 \pm 20.5$ & $3.8 \pm 0.5$ \\
Model & $149.3 \pm 17.2^{\mathrm{a}}$ & $92.6 \pm 13.5^{\mathrm{a}}$ & $9.1 \pm 1.1^{\mathrm{a}}$ \\
Low-dose crocetin & $157.5 \pm 14.6^{\mathrm{a}}$ & $105.4 \pm 13.1^{\mathrm{ab}}$ & $6.9 \pm 0.8^{\mathrm{ab}}$ \\
Middle-dose crocetin & $168.7 \pm 19.1^{\mathrm{ab}}$ & $127.2 \pm 14.7^{\mathrm{ab}}$ & $5.8 \pm 0.7^{\mathrm{ab}}$ \\
High-dose crocetin & $189.1 \pm 12.3^{\mathrm{abcd}}$ & $138.8 \pm 18.1^{\mathrm{abc}}$ & $4.5 \pm 0.7^{\mathrm{abcd}}$ \\
\hline
\end{tabular}

${ }^{a} \mathrm{P}<0.05$ compared with sham-operated group; $\mathrm{b} P<0.05$ compared with model group; ${ }^{\mathrm{C}}<0.05$ compared with low-dose crocetin group; ${ }^{\mathrm{d}} \mathrm{P}<0.05$ compared with middle-dose crocetin group. SOD, superoxide dismutase; GSH-Px, glutathione peroxidase; MDA, malondialdehyde. 


\section{Discussion}

With the application of thrombolytic treatment, coronary artery bypass, percutaneous coronary angioplasty and other vascular reperfuse therapies, the blood supply of myocardial ischemic tissue can be restored. The changes in the period of myocardial ischemia have laid the foundation for the occurrence of reperfusion injury. The reperfusion injury is the continuation, expansion and deterioration of ischemic injury (Jennings, 2013). Therefore, searching for drugs that effectively prevent MIRI has become the research focus of medical scientists. This study investigated the protective effect of crocetin on experimental MIRI in rats. Results showed that, compared with model group, the LVEDP in crocetin groups was significantly decreased, the LVSP, $+\mathrm{d} p / \mathrm{d} t_{\text {max }}$ and $-\mathrm{d} p / \mathrm{d} t_{\text {max }}$ in crocetin groups were significantly increased, and the miocardial infarction size in crocetin groups was significantly decreased. In addition, compared with model group, the serum levels of myocardial injury markers in crocetin groups were significantly decreased. This indicates that, the crocetin pretreatment can reduce the miocardial infarction, improve the cardiac systolic and diastolic function, and mitigate the MIRI.

After myocardial ischemia-reperfusion, the calcium overload, oxygen free radical generation and energy metabolism disorder occur, which are the main causes of MIRI (Inci et al., 2001). TNF- $\alpha$ is a pro-inflammatory factor with negative inotropic action, and is the starting factor of the inflammatory cascade reaction. TNF- $\alpha$ can inhibit the contractile force of cardiac myocytes, thus causing cardiac dysfunction and myocardial injury (Chen et al., 2013). IL-1 $\beta$ is in the upstream factor of inflammatory cascade. It can be produced at the early stage of MIRI. When myocardial injury occurs, the continuous increase of IL- $1 \beta$ level can cause series of pathophysiological changes which reduce the myocardial contractility and aggravate the inflammatory response, ischemia-reperfusion injury and arrhythmia (Xu et al., 2008). IL-6 is one of the important inflammatory mediators produced by leukocytes and endothelial cells, and is at the pivot of inflammation regulation. Compared with C-reactive protein and creatine phosphokinase, IL-6 is more sensitive to the stress response and myocardial injury (McGinnis et al., 2015). In this study, compared with model group, the serum TNF- $\alpha$, IL- $1 \beta$ and IL-6 levels in crocetin groups were significantly decreased. This indicates that, crocetin can decrease the inflammatory response, thus alleviating the MIRI in rats.

It is found that, when the blood supply is interrupted and the energy supply is reduced, the function of oxygen free radical scavenging enzymes, such as catalase, SOD and GSH-Px, is reduced or lost, resulting in increase of oxygen free radicals. When the blood supply is restored, a large number of oxygen free radicals will generate and accumulate, which leads to the lipid peroxidation (Zhang et al., 2003). MDA is the last metabolite of lipid peroxidation induced by oxygen free radicals, and its activity reflects the degree and content of lipid peroxidation of oxygen free radicals. Detection of these indexes can directly reflect the ability of scavenging oxygen free radicals in the body (Tsikas, 2017). Results of this study showed that, compared with model group, the SOD and GSH-Px levels in crocetin groups were significantly increased, and the MDA level was significantly decreased. This indicates that, crocetin has the ability of scavenging radical and reducing lipid peroxidation, thus playing a role in alleviating the MIRI.

Phosphatidylinositol 3-kinase and protein kinase B (PI3K/Akt) signaling pathway plays a key role in cell proliferation, metabolism, and apoptosis (Ma et al., 2013). Bcl-2 family is an important target on the PI3K/Akt signaling pathway (Jin et al., 2004). $\mathrm{Bcl}-2$ and $\mathrm{Bax}$ are the core members of the Bcl-2 family. They play an important role in the development and development of cell apoptosis. Bcl-2 is the main apoptosis-inhibiting protein. It participates in the regulation of apoptotic signal by regulating the integrity of mitochondrial membrane, promote the viability of cardiomyocytes, and inhibit their apoptosis. On the contrary, $\mathrm{Bax}$ acts with $\mathrm{Bcl}-2$ by forming the heteromeric dimers, thus inhibiting Bcl-2 activity and promoting the cell apoptosis (Korsmeyer et al., 1993). After myocardial ischemia, both Bcl-2 and Bax are expressed in cardiomyocytes. The over expression of Bcl-2 can significantly inhibit the apoptosis of cardiomyocytes after MIRI, and reduce the infarction size. The balance between Bcl-2 and Bax plays an important role in the regulation of cell apoptosis. The decrease of $\mathrm{Bcl}-2 / \mathrm{Bax}$ ratio indicates the induction of apoptosis, and the increase of $\mathrm{Bcl}-2 / \mathrm{Bax}$ ratio indicates the inhibition of apoptosis (Schultze et al., 2012). Study has shown that, Akt activation (p-Akt) can promote the formation of $\mathrm{Bcl}-2$ protein, and inhibit the formation of Bax, Bad and Caspases, thus inhibiting the cell apoptosis (Tang et al., 2006). In this study, compared with sham-operated group, in model group the myocardial Bcl-2 protein expression level was decreased, and the Bax protein expression level was increased. In addition, the myocardial p-Akt protein expression level was decreased. Compared with model group, in crocetin groups the $\mathrm{Bcl}-2$ protein level was increased, the Bax protein level was decreased, and the p-Akt protein was increased. This indicates that, the decreased phosphorylation of Akt and increased myocardial apoptosis are involved in the process of MIRI. Crocetin can increase the phosphorylation of Akt and reduce the myocardial apoptosis, thus alleviating the MIRI.

In conclusion, crocetin from Crocus sativus $L$. has protective effects on MIRI in rats. The mechanism may be related to its resistance of inflammatory response, oxidative stress and myocardial apoptosis, and activation of PI3K/Akt signaling pathway in myocardial tissue. This study has provided an experimental basis for the clinical application of crocetin to prevention and treatment of MIRI. The limitations of this study are as follows: Firstly, the correlations among different indexes have not been discussed. Secondly, there are may be other mechanisms of crocetin alleviating MIRI. These issues need to be further investigated.

\section{References}

Chen, J., Chen, Y. H., Lv, H. Y., \& Chen, L. T. (2016). Effect of hyperbaric oxygen on lipid peroxidation and visual development in neonatal rats with hypoxia-ischemia brain damage. Biomedical Reports, 5(1), 136-140. http://dx.doi.org/10.3892/br.2016.673. PMid:27347417.

Chen, W., Liu, N., Qi, Y., Zhang, Y., Deng, Z., Yang, J., \& Xie, X. (2013). Changes of systemic and local myeloperoxidase and tumor necrosis factor- $\alpha$ in rats with myocardial injury induced by hind-limb 
ischemia-reperfusion. Journal of Southern Medical University, 33(5), 761-764. PMid:23689002. Article in Chinese.

Cheng, L., Jin, Z., Zhao, R., Ren, K., Deng, C., \& Yu, S. (2015). Resveratrol attenuates inflammation and oxidative stress induced by myocardial ischemia-reperfusion injury: role of $\mathrm{Nrf} 2$ /ARE pathway. International Journal of Clinical and Experimental Medicine, 8(7), 10420-10428. PMid:26379832.

Fläring, U. B., Rooyackers, O. E., Wernerman, J., \& Hammarqvist, F. (2003). Glutamine attenuates post-traumatic glutathione depletion in human muscle. Clinical Science, 104(3), 275-282. http://dx.doi. org/10.1042/cs1040275. PMid:12605586.

Haugan, K., Marcussen, N., Kjølbye, A. L., Nielsen, M. S., Hennan, J. K., \& Petersen, J. S. (2006). Treatment with the gap junction modifier rotigaptide (ZP123) reduces infarct size in rats with chronic myocardial infarction. Journal of Cardiovascular Pharmacology, 47(2), 236-242. http://dx.doi.org/10.1097/01.fjc.0000200990.31611.6e. PMid:16495761.

Hu, H., Zhai, C., Qian, G., Gu, A., Liu, J., Ying, F., Xu, W., Jin, D., Wang, H., Hu, H., Zhang, Y., \& Tang, G. (2015). Protective effects of tanshinone IIA on myocardial ischemia reperfusion injury by reducing oxidative stress, HMGB1 expression, and inflammatory reaction. Pharmaceutical Biology, 53(12), 1752-1758. http://dx.doi. org/10.3109/13880209.2015.1005753. PMid:25864557.

Inci, I., Dutly, A., Rousson, V., Boehler, A., \& Weder, W. (2001). Trimetazidine protects the energy status after ischemia and reduces reperfusion injury in a rat single lung transplant model. The Journal of Thoracic and Cardiovascular Surgery, 122(6), 1155-1161. http:// dx.doi.org/10.1067/mtc.2001.114941. PMid:11726890.

Jennings, R. B. (2013). Historical perspective on the pathology of myocardial ischemia/reperfusion injury. Circulation Research, 113(4), 428-438. http://dx.doi.org/10.1161/CIRCRESAHA.113.300987. PMid:23908330.

Jin, Y. P., Fishbein, M. C., Said, J. W., Jindra, P. T., Rajalingam, R., Rozengurt, E., \& Reed, E. F. (2004). Anti-HLA class I antibody-mediated activation of the PI3K/Akt signaling pathway and induction of Bcl2 and Bcl-xL expression in endothelial cells. Human Immunology, 65(4), 291-302. http://dx.doi.org/10.1016/j.humimm.2004.01.002. PMid:15120184.

Korsmeyer, S. J., Shutter, J. R., Veis, D. J., Merry, D. E., \& Oltvai, Z. N. (1993). Bcl-2/Bax: a rheostat that regulates an anti-oxidant pathway and cell death. Seminars in Cancer Biology, 4(6), 327-332. PMid:8142617.

Liang, X. Q., Xie, P., Zhang, Y., Shi, T., Yan, T. H., \& Wang, Q. J. (2010). Effects of salidroside on myocardial ischemia/reperfusion injury in rats. Chinese Journal of Natural Medicines, 8(2), 127-131.

Ma, Y., Qin, H., \& Cui, Y. (2013). MiR-34a targets GAS1 to promote cell proliferation and inhibit apoptosis in papillary thyroid carcinoma via PI3K/Akt/Bad pathway. Biochemical and Biophysical Research Communications, 441(4), 958-963. http://dx.doi.org/10.1016/j. bbrc.2013.11.010. PMid:24220341.

McGinnis, G. R., Ballmann, C., Peters, B., Nanayakkara, G., Roberts, M., Amin, R., \& Quindry, J. C. (2015). Interleukin-6 mediates exercise preconditioning against myocardial ischemia reperfusion injury. American Journal of Physiology. Heart and Circulatory Physiology, 308(11), H1423-H1433. http://dx.doi.org/10.1152/ajpheart.00850.2014. PMid:25820396.

Rameshrad, M., Razavi, B. M., \& Hosseinzadeh, H. (2018). Saffron and its derivatives, crocin, crocetin and safranal, a patent review. Expert
Opinion on Therapeutic Patents, 28(2), 147-165. http://dx.doi.org/1 0.1080/13543776.2017.1355909. PMid:28705037.

Schultze, S. M., Hemmings, B. A., Niessen, M., \& Tschopp, O. (2012). PI3K/AKT, MAPK and AMPK signalling: protein kinases in glucose homeostasis. Expert Reviews in Molecular Medicine, 14, e1. http:// dx.doi.org/10.1017/S1462399411002109. PMid:22233681.

Shen, X. C., Y-Lu, Y., \& Qian, Z. Y. (2006). Effects of crocetin on the matrix metalloproteinases in cardiac hypertrophy induced by norepinephrine in rats. Journal of Asian Natural Products Research, 8(3), 201-208. http://dx.doi.org/10.1080/1028602041233128645. PMid:16864425.

Tang, J. M., He, Q. Y., Guo, R. X., \& Chang, X. J. (2006). Phosphorylated Akt overexpression and loss of PTEN expression in non-small cell lung cancer confers poor prognosis. Lung Cancer, 51(2), 181-191. http://dx.doi.org/10.1016/j.lungcan.2005.10.003. PMid:16324768.

Tsikas, D. (2017). Assessment of lipid peroxidation by measuring malondialdehyde (MDA) and relatives in biological samples: Analytical and biological challenges. Analytical Biochemistry, 524, 13-30. http://dx.doi.org/10.1016/j.ab.2016.10.021. PMid:27789233.

Venardos, K. M., Perkins, A., Headrick, J., \& Kaye, D. M. (2007). Myocardial ischemia-reperfusion injury, antioxidant enzyme systems, and selenium: a review. Current Medicinal Chemistry, 14(14), 1539-1549. http://dx.doi.org/10.2174/092986707780831078. PMid:17584062.

Vinten-Johansen, J., Jiang, R., Reeves, J. G., Mykytenko, J., Deneve, J., \& Jobe, L. J. (2007). Inflammation, proinflammatory mediators and myocardial ischemia-reperfusion injury. Hematology/Oncology Clinics of North America, 21(1), 123-145. http://dx.doi.org/10.1016/j. hoc.2006.11.010. PMid:17258123.

Wang, K., Wen, S., Jiao, J., Tang, T., Zhao, X., Zhang, M., Lv, B., Lu, Y., Zhou, X., Li, J., Nie, S., Liao, Y., Wang, Q., Tu, X., Mallat, Z., Xia, N., \& Cheng, X. (2018). IL-21 promotes myocardial ischaemia/ reperfusion injury through the modulation of neutrophil infiltration. British Journal of Pharmacology, 175(8), 1329-1343. http://dx.doi. org/10.1111/bph.13781. PMid:28294304.

Xu, J. M., Tao, L. J., Fu, D., Lv, Z. P., Li, L., \& Dai, R. P. (2008). Activation of interleukin-1 beta (IL-1 beta) signaling in the spinal cord in the rats with experimental cardiac injury. International Journal of Cardiology, 128(3), 413-418. http://dx.doi.org/10.1016/j.ijcard.2007.06.025. PMid:17719662.

Yu, H., Guan, Q., Guo, L., Zhang, H., Pang, X., Cheng, Y., Zhang, X., \& Sun, Y. (2016). Gypenosides alleviate myocardial ischemiareperfusion injury via attenuation of oxidative stress and preservation of mitochondrial function in rat heart. Cell Stress \& Chaperones, 21(3), 429-437. http://dx.doi.org/10.1007/s12192-016-0669-5. PMid:26800973.

Zhai, P., Eurell, T. E., Cooke, P. S., Lubahn, D. B., \& Gross, D. R. (2000). Myocardial ischemia-reperfusion injury in estrogen receptor-alpha knockout and wild-type mice. American Journal of Physiology. Heart and Circulatory Physiology, 278(5), H1640-H1647. http://dx.doi. org/10.1152/ajpheart.2000.278.5.H1640. PMid:10775144.

Zhang, M., Liu, L., Cheng, L., \& Zhang, P. (2003). Express of plasma ROS, SOD and GSH-PX in patients with nasopharyngeal carcinoma. Journal of Clinical Otorhinolaryngology Head and Neck Surgery, 17(11), 650-651. PMid:14971196. Article in Chinese.

Zhang, R., Qian, Z. Y., Han, X. Y., Chen, Z., \& Yan, J. L. (2009). Comparison of the effects of crocetin and crocin on myocardial injury in rats. Chinese Journal of Natural Medicines, 7(3), 223-227. Article in Chinese. 